\title{
Study of the interaction mechanism between Heterodera schachtii and Rhizoctonia solani using a split-pot design on sugar beet
}

\section{Estudio del mecanismo de interacción entre Heterodera schachtii y Rhizoctonia solani mediante el estudio de la disociación radical en remolacha azucarera}
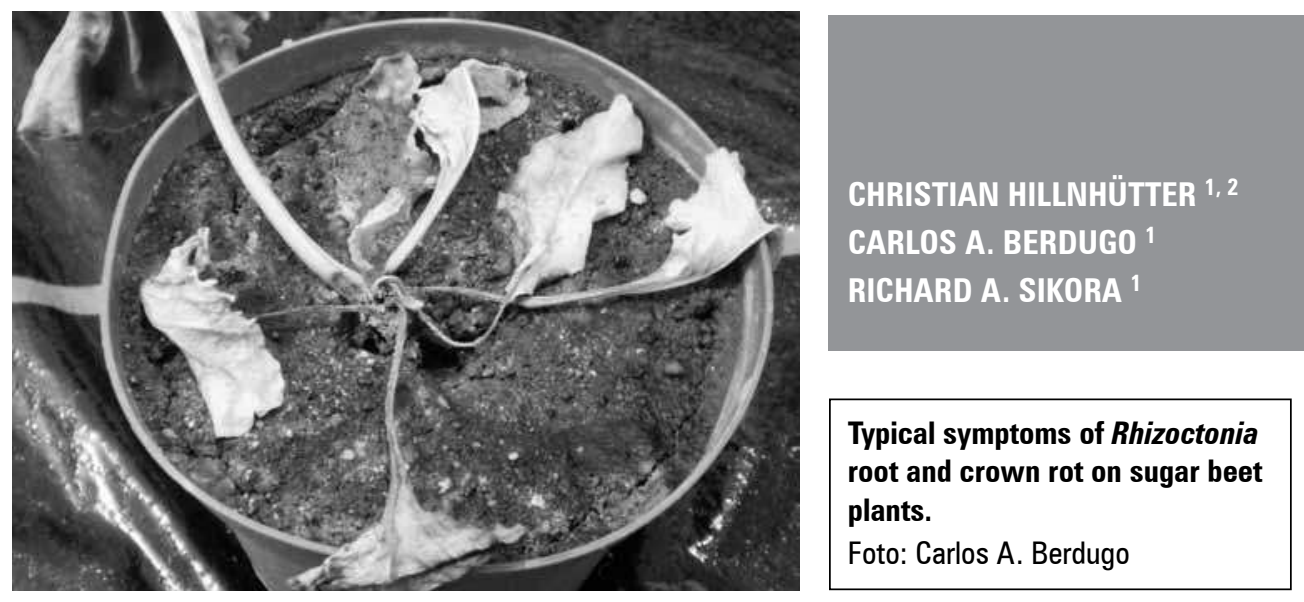

\section{ABSTRACT}

Sugar beet plants were split into two pots to investigate in detail the interactions between Heterodera schachtii and Rhizoctonia solani and to determine if a relationship exists between the two pathogens. Additionally, hyperspectral leaf reflectance measurements were taken to detect symptoms caused by soil-borne pathogens. The results indicate a direct interaction between the nematode and the fungus. Treatments with both organisms together presented the most severe plant damage. By using leaf reflectance and calculation of the vegetation index, it was possible to establish differences between the treatments. This is a promising result for further studies, which will be useful for the detection and discrimination of symptoms caused by plant pathogens.

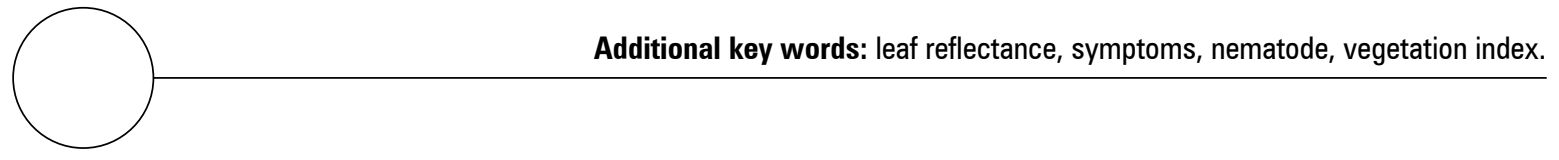

Rheinische Friedrich-Wilhelms-Universität Bonn, Institute of Crop Science and Resource Conservation (INRES) Phytomedicine, Bonn (Germany)

2 Corresponding author.chillnhu@uni-bonn.de 


\section{RESUMEN}

Plantas de remolacha azucarera se dividieron en dos macetas con el objetivo de investigar en detalle la relación entre Heterodera schachtii and Rhizoctonia solani, y determinar si existe una relación entre estos dos patógenos. Adicionalmente se evaluó la reflectancia foliar para detectar síntomas causados por patógenos del suelo. Los resultados obtenidos indican una relación directa entre el nematodo y el hongo. Los tratamientos inoculados con los dos organismos fueron los que presentaron los daños más severos. Mediante la reflectancia foliar y el cálculo del índice de vegetación fue posible establecer diferencias entre tratamientos. Estos resultados son promisorios para subsecuentes experimentos, los cuales serán útiles para la identificación y detección de síntomas causados por patógenos de plantas.

Palabras clave adicionales: reflectancia foliar, síntomas, nematodo, índice de vegetación.

Fecha de recepción: 07-01-2011

Aprobado para publicación: 27-05-2011

INTRODUCCIÓN

The beet cyst nematode (BCN) Heterodera schachtii (Schmidt) causes severe damage to sugar beet plants with yield losses of up to $25 \%$ and is still considered the most important pest in sugar beet production worldwide (Cooke, 1987; Schlang, 1991). Belowground symptoms include the development of compensatory secondary roots that result in the typical "bearded" root symptom and an overall beet deformity (Decker, 1969; Cooke, 1987). When removed from the soil, white or brown citrus shaped females or cysts can be observed attached to the roots.

Rhizoctonia crown and root rot (RCRR) caused by Rhizoctonia solani Kühn (teleomorph Thanatephorus cucumeris [Frank] Donk) AG 2-2IIIB (Ogoshi, 1996) is one of the most important sugar beet diseases in the world and causes yield losses of up to 50\% (Herr, 1996; Büttner et al., 2004). In the USA up to $24 \%$ of the sugar beet cropping area is endangered by RCRR and in the European Union $5 \%$ of the sugar beet areas are infested (Harveson, 2008). First symptoms include wilting, chlorosis and black constrictions on the petioles near the crown of the beet (Zens et al., 2002). Wilted leaves collapse, developing a rosette of necrotic leaves around the beet crown. Rotting typically progresses from the petioles to the crown and then down into the beet and lateral roots.

A differentiation between direct and indirect interaction of the organisms within the disease complex need to be investigated (Hillnhütter et al., 2011). Indirect interactions are initiated by the changes that each organism causes to the plant on which both depend (Pitcher, 1978). Direct interactions imply that the nematode is a vector of the pathogen; the pathogen enters the plant through wounding caused by the nematode (Bergeson, 1972; Barker and McGawley, 1998). Stress on the plant can also decrease plant resistance and cause increased damage. Direct interactions between RCRR of $R$. solani (AG 2-2) and $H$. schachtii are arguable, due to the places that are attacked by the organisms. The nematode penetrates the plants at the lateral root (Franklin, 1972) or often behind the root tip in the elongation zone (Moriarty, 1964; Cooke, 1993). Due to Baker (1970) and Herr (1996) RCRR starts invading the plant at petioles of leaves above ground. Still, it is unclear what exactly happens in terms of infection processes in the soil. 
Experimental designs for investigation of disease complexes often include; bridging, layering, or grafting of roots or stem tissues, and doubleroot or split-root techniques (Khan, 1993). A spatial separation of organisms on one plant by splitting the beet was comprised by this study. It should be distinguished between a direct or indirect interaction of the organisms. Split root experiments were realized according to studies on interactions among soil-borne organisms and induced resistance (Hallmann and Berg, 2006; Khan, 1993; Vu et al., 2006,).

Hyperspectral leaf reflectance was recorded to calculate the vegetation index NDVI. This index was then tested on suitability to discriminate symptoms caused by either organism alone or in combination by means of leaf reflectance.

\section{MATERIALS AND METHODS}

\section{Plant material}

Plants of sugar beet cultivar Alyssa (susceptible, KWS GmbH, Einbeck, Germany) were grown in multipots for 8 weeks to obtain vigorous plants with a bigger beet body. With 8 weeks the plants were removed from the multipots and subsequently soil was washed with tap water off beets and roots. The roots were shortened with a sterile scalpel blade to a length of one centimeter. Additionally, the beet was split with the scalpel blade from inferior to superior, up to one centimeter below leaf axil (figure 1). The splitted plants were then carefully transferred into two chamber biotest vessels of $12 \mathrm{~cm}$ depth and $5 \times 5 \mathrm{~cm}$ area (Behringer, 1967). These vessels were kept together with elastic band. The splitted beet was divided on the two biotest vessels. The experiments were conducted at $25 / 20^{\circ} \mathrm{C}$ (day/night), a relative humidity of $70 \pm 10 \%$ and a photoperiod of $12 \mathrm{~h} \mathrm{~d}^{-1}\left(>300 \mu \mathrm{mol} \mathrm{m} \mathrm{m}^{-2}\right.$, Phillips SGR 140, Hamburg, Germany). Plants were fertilized every 2 weeks with $50 \mathrm{~mL}$ of a

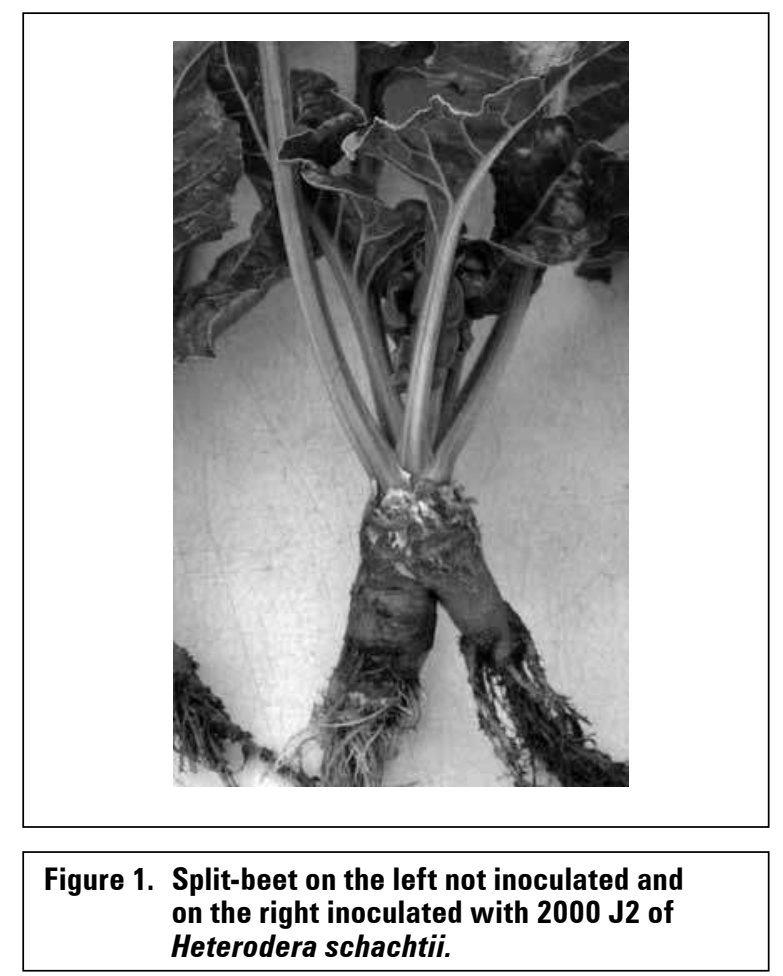

$2 \%$ NPK fertilizer $\left(18+12+18\right.$, Flory ${ }^{\circledR} 3$ Mega, Euflor, Munich, Germany).

The experiment consisted of five treatments eight plants each and was repeated. The first treatment was negative control without inoculation (i). In the second and third treatment one of the two test vessels was inoculated with either one of the organisms (ii; iii). For the fourth treatment in one vessel the nematode and in the other the fungi was inoculated (iv) and in the fifth treatment to both biotest vessels half of the amount of inoculum was given (v).

\section{Organisms}

Heterodera schachtii was obtained from the institutes' stock cultures. Nematodes were multiplied on Brassica napus cultivar Akela (Feldsaaten Freudenberger, Krefeld, Germany) in greenhouse pots filled with sterilized sand. Cysts were extracted using a standard wet-screen decantation method and then transferred to Oostenbrink 
dishes filled with $5 \mathrm{mM} \mathrm{ZnCl}_{2}$-solution for seven days to stimulate J2 emergence (Oostenbrink, 1960). The J2 were collected in $25 \mu \mathrm{m}$ size sieves (Retsch, Haan, Germany), counted under the microscope and used directly for inoculation. $2000 \mathrm{~J} 2$ of $H$. schachtii were inoculated into cavities ( $4 \mathrm{~cm}$ deep) in the soil with a pipette tip near the base of the plant.

Rhizoctonia solani anastomosis group 2-2IIIB was taken from pure isolates, and after two weeks growth on petri dishes, four pieces of $7 \mathrm{~mm}$ diameter were transferred under sterile conditions to Erlenmeyer flasks, containing 250 $\mathrm{mL}$ of PDB medium (Potato Dextrose Broth, Becton Dickinson, Franklin Lakes, NY). The medium was previously autoclaved at $121^{\circ} \mathrm{C}$ for 20 min. Flasks were shaken moderately at 100 $\mathrm{rpm}$ on a shaker placed at $25^{\circ} \mathrm{C}$ in the dark. After $15 \mathrm{~d}$, mycelium was taken from the medium by sieving the content of the Erlenmeyer flask through a sterile $5 \mu \mathrm{m}$ pore size filter-paper. The mycelium was dripped off and subsequently homogenized in a blender (Waring Products, Torrington, CT) in order to make a stock solution (2 $\mathrm{mg}$ of $R$. solani mycelium per $1 \mathrm{~mL}$ of tap water). Each plant was then inoculated with 3 $\mathrm{mL}$ of stock solution in a cavity beside the beet crown. Experiments were harvested after 5 weeks ((Berdugo, 2009).

\section{Disease severity and plant fresh weight}

At termination of experiments the variables leaf and beet fresh weight were determined. The number of nematodes was determined after Hillnhütter et al. (2011). Severity of $R$. solani beet rot was estimated for each beet based on Zens et al. (2002) scale of: $0=$ healthy, no symptoms to $6=$ beet completely rotten, plant dead.

The leaf and the beet fresh weight and the RCRR rating values and the number of eggs and J2 per plant were compared using Tukey's test, with a significance level of $P \leq 0.05$.

\section{Hyperspectral data acquisition and analysis}

Hyperspectral reflectance of the foliage was measured at 7 and $25 \mathrm{~d}$ past inoculation using a handheld spectrometer with a foreoptic contact probe and a leaf-clip holder (ASD FieldSpec Pro spectrometer, Analytical Spectral Devices Inc., Boulder, CO). The contact probe foreoptic had a $10 \mathrm{~mm}$ spot size and an integrated halogen bulb light source. The ASD FieldSpec had a measuring range of 400-1,050 $\mathrm{nm}$ and a spectral resolution of $1,421 \mathrm{~nm}$. Sample reflectance was obtained by inserting a leaf into the leaf-clip and comparing leaf reflectance to the reflectance of a dark current as a minimum value and to the reflectance of the white standard (Spectralon Reflectance Standards, Labsphere, North Sutton, $\mathrm{NH})$. Spectra of eight plants per treatment were recorded and each measurement was the average of 10 scans. The measurements were always made on the same leaves of similar age.

Hyperspectral data were exported as ASCII file using the software ASD ViewSpecPro (Analytical Spectral Devices Inc., Boulder, CO) and then transferred to MS Office Excel where the Normalized Differentiated Vegetation Index (NDVI) was calculated. NDVI was developed by Rouse et al. (1974) to detect vegetation changes by comparing the reflectance of the strong light absorbing red region (RED) and the low light absorbing near infrared region (NIR) of plants, where RED was in the 620$640 \mathrm{~nm}$ band and NIR in the 740-760 $\mathrm{nm}$ band.

$N D V I=\frac{(N I R-R E D)}{(N I R+R E D)}$

was calculated for all treatments from the spectral signatures recorded and is displayed in the results in figure 3.

\section{RESULTS}

In this experiment it should be determined between a direct or indirect interaction among 
H. schachtii and $R$. solani. The results indicate a direct interaction. Treatment $v$ with the two organisms inoculated in both vessels, had significant less beet and leaf weight than all other treatments $(i-i v)$ (table 1$)$.

The data of eggs and J2 per plant and the R. solani beet rot rating showed no significant differences in this experiment.

Hyperspectral leaf reflectance showed differences among the treatments. The treatment with both organisms together in the biotest vessels had by far the strongest increase of reflectance in the VIS and also NIR. Treatment $v$ showed the highest increase of leaf reflectance in the red region of VIS and NIR (figure 2). All other treatments showed just marginal differences in leaf reflectance over the time.

NDVI data showed difference in vitality between treatments, especially in treatment $v$ at the lowest values (figure 3).

\section{DISCUSSION}

The objective was to determine among a direct or indirect interaction between Heterodera

Table 1. Leaf and beet fresh weight of split sugar beet plants treated either as control, inoculated with Heterodera schachtii; Rhizoctonia solani or concomitant inoculation with both organisms. Displayed are the means \pm standard errors of each treatment. Different letters indicate significant difference after Tukey's test $(P \leq 0.05 ; n=8)$.

\begin{tabular}{|l|c|c|}
\hline \multicolumn{1}{|c|}{ Treatment } & Leaf $[\mathrm{g}]$ & Beet [g] \\
\hline Control $[\mathrm{i}]$ & $12.1 \pm 1.5 \mathrm{a}$ & $16.4 \pm 1.9 \mathrm{a}$ \\
\hline Heterodera schachtii $[i \mathrm{i}]$ & $10.9 \pm 0.5 \mathrm{ab}$ & $13.5 \pm 1.0 \mathrm{ab}$ \\
\hline Rhizoctonia solani $[i i i]$ & $8.6 \pm 1.3 \mathrm{abc}$ & $12.9 \pm 1.7 \mathrm{abc}$ \\
\hline H. schachtii + R. solani either one vessel $[i \mathrm{iv}]$ & $6.1 \pm 1.3 \mathrm{bc}$ & $9.3 \pm 1.6 \mathrm{bc}$ \\
\hline H. schachtii + R. solani both vessels $[\mathrm{v}]$ & $4.1 \pm 1.2 \mathrm{c}$ & $6.1 \pm 1.8 \mathrm{c}$ \\
\hline
\end{tabular}

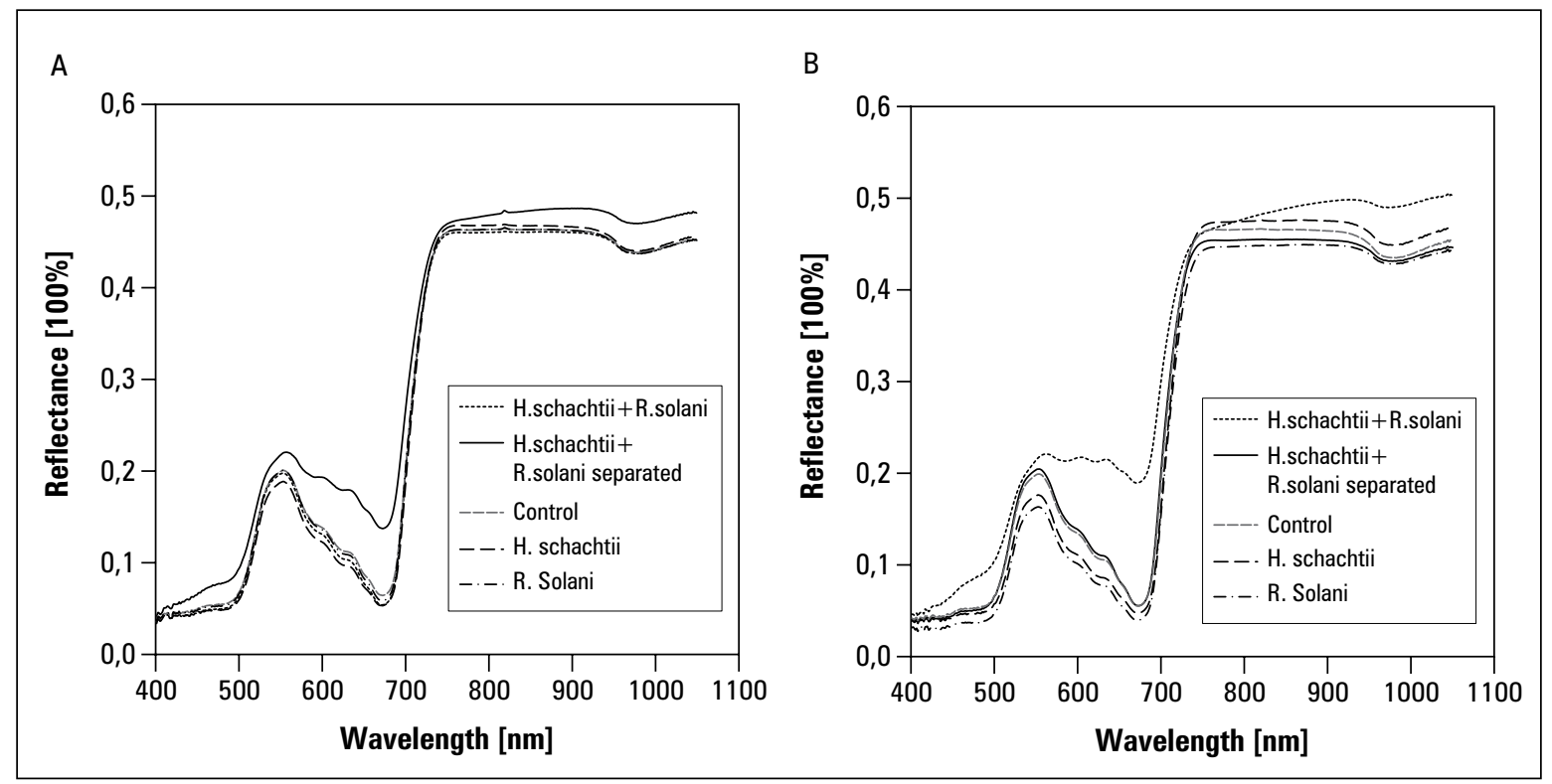

Figure 2. Effect of Heterodera schachtii, Rhizoctonia solani and their spatial separation or combination on one plant on leaf reflectance values A: 7dpi and B: $25 \mathrm{dpi}$. 


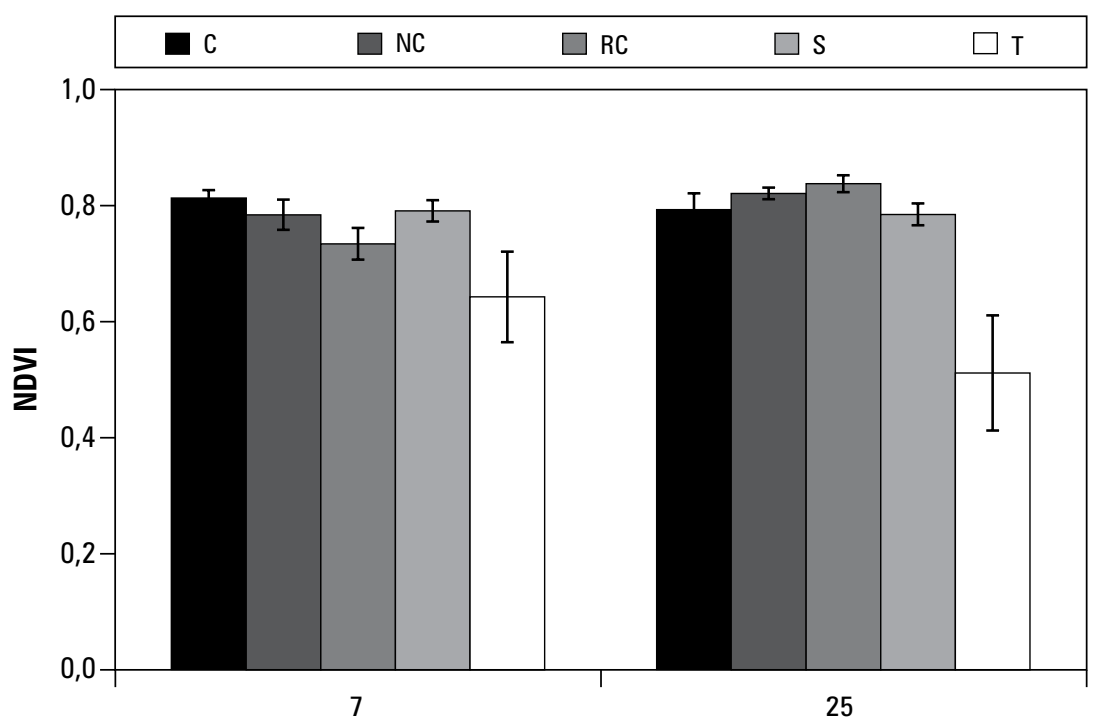

Figure 3. Effect of Heterodera schachtii, Rhizoctonia solani and their spatial separation or combination on one plant on NDVI values 7dpi and 25dpi [C $=$ Control; NC $=$ Nematode control; $R C=$ Rhizoctonia control; S $=$ Seperated organisms; $\mathrm{T}=$ not separated organisms].

schachtii and Rhizoctonia solani on sugar beet. Direct interaction would be a penetration of $H$. schachtii in the plant and in this penetration hole $R$. solani also enters the plant, as reported by Polychronopoulos et al. (1969). Indirect would be an attack of both organisms at different parts of the plant, but too much stress caused of two organisms the disease develops faster. The results devoted a direct interaction among the organisms (Polychronopoulos et al., 1969; Bergeson, 1972). However, the exact interaction pattern is still unclear and needs further investigation, because of the findings of Cooke (1993) and Herr (1996) in contrast to results of Polychronopoulos (1969). The experiments of Polychronopoulos (1969) were conducted in aseptic conditions, which change the behavior of experimental organisms. It would also be possible that direct and indirect interactions were parallel present in this disease complex. The results allow the interpretation of direct and indirect interaction parallel, because treatment iv had worse results than each of the control treatments. However, in further studies microscopic trials have to be realized of different aged plants grown under natural conditions to attest the mode of action. In potato an increased production of root exudates by nematode penetration was shown by Bhattarai et al. (2009). This increased attraction of the plant to $R$. solani and to attack the plant. The influence on root exudates by disease complex has to be analyzed in further experiments. By nematode penetration into the plants, for sure liquid plant exudates exit the plants. These sugars would be a good attractant to the fungi.

The leaf reflectance approved the balanced plant weight at termination of experiment and seemed to be a good predicator for plant stress. The RCRR leaf symptoms included the typical symptoms of yellowing, wilting and necrosis of leaves resulting from modifications in chlorophyll, carotenoid and water content of leaves. The differences between treatments obtained with NDVI confirmed its suitability as an indicator for disease development (Hillnhütter and Mahlein, 2008). Heath et al. (2000) reported cor- 
relations between the number of juveniles of potato cyst nematodes in the roots of potato and NDVI of leaf reflectance measurements.

In the present study it was not possible to discriminate between $H$. schachtii damage over the non-inoculated controls. Discrimination might be possible when: higher initial inoculum densities are used, in older beets when multiple generations have developed or under water and heat stress growing conditions when damage is greater.

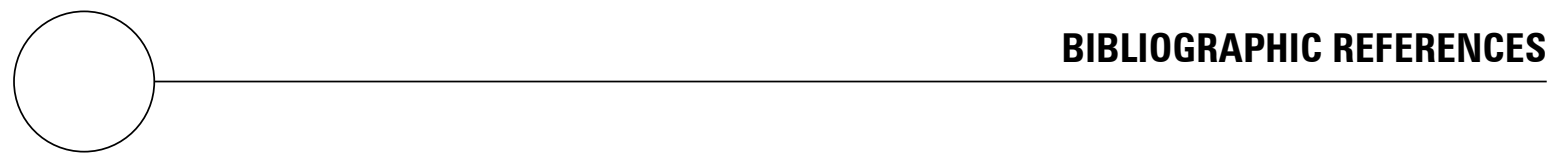

Baker, K.F. 1970. Types of Rhizoctonia diseases and their occurrence. pp. 125-148. In: Parmeter, J.R. (ed.). Rhizoctonia solani: Biology and pathology. University of California Press, Los Angeles, CA.

Barker, K.R. and E.C. McGawley. 1998. Interrelations with other microorganisms and pests. pp. 266-292. In: Sharma, S.B. (ed.). The cyst nematodes. Kluwer Academic Publishers, Dordrecht, The Netherlands.

Behringer, P. 1967. Der Biotest-Nematodennachweis mit Zukunft. Kartoffelbau 18, 170-172.

Berdugo, C.A. 2009. Establishment of a screening test for resistance of sugar beet to Rhizoctonia solani AG 2-2IIIB and AG 4. M.Sc. thesis. University of Bonn, Germany.

Bergeson, B.B. 1972. Concepts of nematode-fungus associations in plant disease complexes: A review. Exp. Parasitol. 32, 301-314.

Bhattarai, S., P.P.J. Haydock, M.A Back, M.C. Hare and W.T. Lankford, 2009. Interactions between the potato cyst nematodes, Globodera pallida, G. rostochiensis, and soil-borne fungus, Rhizoctonia solani (AG3), diseases of potatoes in the glasshouse and the field. Nematol. 11, 631-640.

Büttner, G., B. Pfähler, and B. Märländer. 2004. Greenhouse and field techniques for testing sugar beet for resistance to Rhizoctonia root and crown rot. Plant Breeding 123, 158-166.

Cooke, D.A. 1987. Beet cyst nematode (Heterodera schachtii Schmidt) and its control on sugar beet. Agr. Zool. Rev. 2, 135-183.

Cooke, D.A. 1993. Nematode parasites of sugarbeet. pp. 133-170. In: Evans, K., D.L. Trudgill, and J.M. Webster (eds.). Plant parasitic nematodes in temperate agriculture. CABI Publishing, Wallingford, UK.
Decker, H. (ed.). 1969. Phytonematologie - Biologie und Bekämpfung pflanzenparasitärer Nematoden. Deutscher Landwirtschaftsverlag, Berlin. pp. 231239.

Franklin, M.T. 1972. CIH descriptions of plant parasitic nematodes Set 1, No. 1. Cabi Publishing, Wallingford, UK.

Hallmann, J. and G. Berg, 2006. Spectrum and population dynamics of bacterial root endophytes. pp.1531. In: B. Schulz, C. Boyle and T.N. Sieber (Eds). Soil Biology. Springer, Berlin.

Harveson, R.M. 2008. Rhizoctonia root and crown rot of sugar beet. Published by University of Nebraska-Lincoln Extension, Institute of Agriculture and Natural Resources. En: http:// elkhorn.unl.edu/epublic/pages/publicationD. jsp?publicationId =995; accessed on October 2010 .

Heath, W.L., P.P.J. Haydock, A. Wilcox, and K. Evans. 2000. The potential use of spectral reflectance from the potato crop for remote sensing of infection by potato cyst nematodes. Aspects Appl. Biol. 60, 185-188.

Herr, L.J. 1996. Sugar beet diseases incited by Rhizoctonia species. pp. 341-349. In: Sneh, B., S. Jabaji-Hare, S. Neate, and G. Dijst (eds.). Rhizoctonia species: Taxonomy, molecular biology, ecology, pathology and disease control. Kluwer Academic Publishers, Dordrecht, The Netherlands.

Hillnhütter, C. and A.K. Mahlein. 2008. Early detection and localization of sugar beet diseases: new approaches. Gesunde Pflanzen 60, 143-149.

Hillnhütter, C., R.A. Sikora, and E.-C. Oerke. 2011. Influence of different levels of resistance or tolerance in sugar beet cultivars on complex interactions between Heterodera schachtii and Rhizoctonia solani. Nematol. 13, 319-332. 
Kahn, M.W. (ed.). 1993. Nematode interactions. Chapman and Hall, New York, NY.

Moriarty, F. 1964. The monoxenic culture of beet eelworm (Heterodera schachtii Schm.) on excised roots of sugar beet (Beta vulgaris L.). Parasitol. 54, 289293.

Ogoshi, A. 1996. Introduction - the genus Rhizoctonia. pp. 1-11. In: Sneh, B., S. Jabaji-Hare, S. Neate, and G. Dijst (eds.). Rhizoctonia species: Taxonomy, molecular biology, ecology, pathology and disease control. Kluwer Academic Publishers, Dordrecht, The Netherlands.

Oostenbrink, M. 1960. Estimating nematode populations by some elected methods. pp. 85-102. In: Sasser, J.N. and W.R. Jenkins (eds.). Nematology. University of North Carolina Press, Chapel Hill, NC.

Pitcher, R.S. 1978. Interactions of nematodes with other pathogens. In: Southey, J.F. (Ed). Plant nematology. Her Majesty's Stationery Office, Ministry of Agriculture, Fisheries and Food, London, UK, pp. 63-77.

Polychronopoulos, A.G., B.R. Houston, and B.F. Lownsberry. 1969. Penetration and development of Rhi- zoctonia solani in sugar beet seedlings infected with Heterodera schachtii. Phytopathol. 59, 482-485.

Rouse, J.W., R.H. Haas, J.A. Schelland and D.W. Deering. 1974. Monitoring vegetation systems in the Great Plains with ERTS. Proceedings of the Third Earth Resources Technology Satellite-1 Symposium. December 1973, Greenbelt, Maryland, USA.

Schlang, J. 1991. Anbau resistenter Zwischenfrüchte zur biologischen Bekämpfung des Rübenzystennematoden. Zuckerrübe 40, 476-488.

Vu, T., R., Hauschild, and R.A. Sikora. 2006. Fusarium oxysporum endophytes induced systemic resistance against Radopholus similis on banana. Nematol. 8, 847-852.

Zens, I., U. Steiner, and H.-W. Dehne. 2002. Auftreten, Charakterisierung und Kontrolle des Erregers der Rübenfäule, Rhizoctonia solani, in Nordrhein-Westfalen. Schriftenreihe des Lehr- und Forschungsschwerpunktes USL 91. Landwirtschaftliche Fakultät der Universität Bonn, Alemania. 